\title{
Animal Evolution all Over the Place, or What is Integrative Biology?
}

\author{
Telford, Maximilian J. and Littlewood, D.T.J.: Animal Evolution: Genomes, Fossils, and \\ Trees. Oxford: Oxford University Press, 2009. Pp. xvi +245 . H/b $\$ 80.00$
}

\section{Joel Cracraft}

Published online: 23 August 2011

(C) Springer Science+Business Media, LLC 2011

There have been a lot of animals (metazoa) throughout Earth's history and there are still a lot with us today. Incredibly we don't know how many there are, even to an order of magnitude. Suffice to say, if most of life is extinct, then we are really talking about a group that could easily contain a billion or more species over its 500-600-millionyear existence. Incredible indeed!

So any discussion about the evolution of animals is a very big topic, thus you have to pick and choose, and that's what this book does. Its own history started as a 2007 symposium organized by Max Telford and Tim Littlewood at the Royal Society of London to celebrate Linnaeus' 300th birthday, moved on to publication in the Philosophical Transactions of the Royal Society B in 2008 (vol. 363, no. 1,496), and now appears in this volume one year later, which means it can also celebrate the bicentenary birth of Charles Darwin, thus doubling its responsibility. Along the way, from the Transactions to this book, authors have been gained and lost, or switched around, some titles and text have changed, but mostly there is a close match. If you read one, you pretty much have read both.

Compared to the symposium, the editors of this book have tried to create some semblance of order to the sequence of papers. Part 1 is ostensibly about the origins of animals, part 2 is about the bilateria, and part 3 about... well...about everything else (called "Themes and perspectives," which also includes papers about animal origins as well as the bilateria). The editors can be excused here, as

\footnotetext{
J. Cracraft $(\bowtie)$

Department of Ornithology,

American Museum of Natural History,

Central Park West at 79th Street,

New York, NY 10024, USA

e-mail: jlc@amnh.org
}

there really is no best way to organize these contributionsthe topic of animal evolution is so vast and these papers are rather topical and represent the work of key scientists in the field. The subtitle also does not quite capture the content, which to this reader is trees (a little), genomes (a little), fossils (a little), and evolutionary development, or EvoDevo (a lot). The unique aspect of the volume is that the editors sought integration across these disciplines and for the most part got it (but see below).

Following an introduction by Telford and Littlewood, there are 18 chapters, the last being a short summary by the editors. As might be expected, given the birth of this volume at the Royal Society, the editors have assembled a group of distinguished scientists who have made important contributions to the study of animal evolution. The editors note that they shaped the expertise of the participants "to promote dialogue between systematists, paleontologists, and evolutionary developmental biologists, reflecting our own interests but also...where collaboration is driving a greater understanding of animal evolution," and in general they chose authors who have had interactions, overlapping interests, and collaborations at multiple times in the past.

It would be fair to say that the purpose of these papers was not to introduce "new" findings but to summarize and "synthesize." All do a good job of describing how their fields have progressed (up to 2007-2008), and for the most part, they look at their specific research interests with the bigger picture in mind. There is considerable disciplinary cross-talk in the contributions. This is exemplified in part 1 , "Origins of animals," with its four chapters: earliest fossil record and the environmental causes underlying the Cambrian explosion in animal diversity (Graham Budd); origin of bilaterians from the perspective of paleontology and genetics (Kevin Peterson and colleagues); insight into metazoan origins from phylogenomics and cell biology 
(Scott Nichols and colleagues); and Hejnol and Martindale explore animal "openings" (mouth, anus, blastopore) from a phylogenetic and developmental perspectives. In part 2, "The Bilateria," there are six chapters: origins of the metazoan body plan from an EvoDevo perspective (Rudy Raff); a phylogenomic approach to resolving relationships of the spiralia (lophotrochozoans; with spiral cleavage) by Gonzalo Giribet and colleagues; evolution of the central nervous system using neuro- and developmental biology (Detlev Arendt and colleagues); origin and relationships of the ecdysozoa using sequence information; Andrew Smith and Billie Swalla look at deuterostome phylogeny from the point of view of paleontology, morphology, and EvoDevo; and Christopher Lowe examines deuterostome evolution from the perspective of hemichordate development. Finally, in part 3 ("Themes and perspectives") eight chapters address a variety of topics: Ronald Jenner and Tim Littlewood address the important topic of the phylogenetic placement of problematic taxa, especially those known by fossils. Touching on the kinds of evidence used to resolve phylogenetic uncertainty, Nicolas Lartillot and Hervé Philippe explore alternative methods of analyzing phylogenomic data. And in a similar vein Jeffrey Boore and Susan Fuerstenberg discuss the usefulness of genome-level changes (gene rearrangements, gene content, and insertions/deletions, among others) as characters in phylogenetics. Richard Copley then presents a general EvoDevo perspective of major genomic changes having developmental consequences for the phenotype. Back to phylogenetics, Erik Sperling and Kevin Peterson introduce us to microRNAs (miRNAs) as a new source of data for phylogenetics at various taxonomic levels across the Tree of Life. Andrew Peel revisits EvoDevo to discuss the evolution of developmental networks, particularly in insects. And then in the following chapter, Patricia Beldade and Suzanne Saenko also take an EvoDevo approach to examine conserved developmental processes in butterflies and their role in the evolution of novel traits. Finally, in Max Telford and Tim Littlewood's summary they argue that integration among the "four dimensions" treated in this book-phylogenetics, paleontology, genomics and EvoDevo - are "resulting in a return to whole-organism biology where the link between genotype and phenotype is considered in the context of changing physical and biological environments." A lofty vision, worthy of editors!

There is little question that many investigators today see great excitement in combining observations and inferences from phylogenetics, paleontology, and EvoDevo, and that view is clearly manifested in this book and the research of the participants. "Integration" is an overused buzzword but the fact that investigators in different disciplines are talking to one another, and actually making use of other kinds of data, is leading to measurable advances. Arguably, the entire field of EvoDevo has arisen from within this interdisciplinary context.

It has to be admitted, however, that much of the "integration" we see in evolutionary biology is pretty thin causally. Indeed, in many instances "integration" is little more than a substitute for "comparative." With the rise of Tree of Life research, phylogenetic trees have become ubiquitous, which has resulted in a cottage industry of investigators taking their favorite tree and optimizing their data on it. This certainly has led to new insights about the history of structural/functional systems, but it is more using, than integrating, something akin to a systematist optimizing morphology on a tree built from gene sequences and then making inferences about morphological evolution. There is nothing wrong with this, but as a healthy literature on this attests, it is not the same as combining ("integrating"?) the data and seeing how they synergistically can be brought to bear on a problem. This form of integration, seen in some of the contributions in this book, will only lead us so far, especially if one discipline becomes the handmaiden of another. Within EvoDevo, at least, integration will steadily increase because of advances in genomic analysis of developmental pathways as well as in bioinformatics, which with developmental ontologies based on homology will allow EvoDevo itself to be merged more fully with traditional genetic and phenotypic data.

I would certainly recommend this book to advanced undergraduate and graduate students in a seminar setting, but the idiosyncratic nature of the book's organization would have to be addressed with additional readings. This is often the fate of symposia, and the volume itself could have used more integration. Still, this does not detract from an interesting group of papers. 